\title{
Intelligence Collection: How to Plan and Execute Intelligence Collection in Complex Environments. By Wayne Michael Hall and Gary Citrenbaum. Santa Barbara, CA, ABC-CLIO, LLC. 2012.
}

Harry I. Nimon Ph.D.

Henley-Putnam University

Follow this and additional works at: https://digitalcommons.usf.edu/jss

pp. 129-131

\section{Recommended Citation}

Nimon, Harry I. Ph.D.. "Intelligence Collection: How to Plan and Execute Intelligence Collection in Complex Environments. By Wayne Michael Hall and Gary Citrenbaum. Santa Barbara, CA, ABC-CLIO, LLC. 2012.." Journal of Strategic Security 6, no. 3 (2013) : 129-131.

DOI: http://dx.doi.org/10.5038/1944-0472.6.3.14

Available at: https://digitalcommons.usf.edu/jss/vol6/iss3/14

This Book Review is brought to you for free and open access by the Open Access Journals at Digital Commons @ University of South Florida. It has been accepted for inclusion in Journal of Strategic Security by an authorized editor of Digital Commons @ University of South Florida. For more information, please contact digitalcommons@usf.edu. 
Intelligence Collection: How to Plan and Execute Intelligence Collection in Complex Environments. By Wayne Michael Hall and Gary Citrenbaum. Santa Barbara, CA, ABC-CLIO, LLC. 2012. 
Intelligence Collection: How to Plan and Execute Intelligence Collection in Complex Environments. By Wayne Michael Hall and Gary Citrenbaum. Santa Barbara, CA, ABCCLIO, LLC. 2012. ISBN 978-0-313-39817-9 (hardback); 978-0-313039818-6 (e-book). Notes, Sources cited. Index. Pp xv, $505 . \$ 63$ (hardback); \$50 (e-book).

Wayne Michael Hall is a retired Army Intelligence brigadier general (BG) who served in various positions to include the $\mathbf{J} 2$ of US Army Forces Korea. He received an Ed.D from George Washington University and is the author of Stray Voltage: War in the Information Age and coauthor of Intelligence Analysis: How to Think in Complex Environments. Coauthor, Gary Citrenbaum, is the president and chief scientist of System of Systems Analytics, Inc. This company focuses on technical intelligence issues. Dr. Citrenbaum received his degree from Virginia Polytechnic Institute.

This book tries to be a monograph on the whys and hows of establishing collection operations primarily in urban environments against unconventional warfare threats. The principal author, BG Hall, has a depth of experience in the Intelligence Community from an operational perspective. His career in the US Army spans approximately thirty years where he had positions from S2 to J2. Dr. Citrenbaum is somewhat of a mystery. Searches on-line only reveal his position with his corporation and the coauthored texts. Thus, his relevancy to this work is undetermined. From reviews on the other books coauthored by Dr. Citrenbaum, it would appear that his contribution is in the analytical realm while BG Hall's is operational.

This particular work is a continuation on the theme of what BG Hall establishes as knowledge war and is presented in a construct that is very reminiscent of the Semiotics Philosophy thinking as espoused by Charles Sanders Pierce. There are many researchers and philosophers who embrace this philosophy, opposing, in their view, the antiquated and wrong-thinking approaches of the scientific methodology as either passé or even totally erroneous. This particular book embraces the aspects of advanced thinking espoused by Pierce and others, yet appears to neglect the necessities of true cognitive science. The authors attempt to establish what they believe is a new and dynamic functionality to the process of collecting information and turning it into intelligence. Their text relates to, yet establishes as antiquated, an analytical process that has been successful for thousands of years. The basic gist of this review is that of King Solomon (or possibly another individual named Koheleth) who stated in Ecclesiastes 1:9, "What has been will be again, what has been done will be done again; there is nothing new under the sun."

The authors state in their introduction that; "This is a book about change - change in our [the intelligence community's] metacognition ... that forms the basis for how we think about intelligence collection operations" (p. 1). They posit this new structure in what they term advanced analysis/advanced collection practices. A few sentences later, the aspect of advanced collection is defined as, "[finding] subtle, nuanced, and often fleeting observables indicting the presence and activities of well-obscured adversaries, and the often subtle outcomes of commanders' actions and verbal interactions with the contested populace [semiotics] ..." (p. 2).

While this is a laudable goal, it is no different from the philosophy of any other analytical process, particularly those involving military intelligence operations. What is particularly daunting is that within its premise is the theorem that logical analysis in an advanced format is 
necessary to the survival of American intelligence organs, and that any failure of these organs to adopt the changes identified in this text "are failing to take advantage of one of the greatest capabilities of the United States" (p. 6). This statement is, in itself, a logical fallacy.

For the next seventy-five pages, the text drives through a matrix of acronyms and repeated concepts making it a very difficult read; even for someone who enjoys texts such as this one. It wasn't until completing the first seventy-five pages that it became clear that the relationship between advanced analysis and advanced collection is simply the ability to use logic to pull information together to form precognitive intelligence of an enemy's intentions, which is and has been the basis of intelligence operations since Moses sent Joshua into Canaan.

Most such texts establish their philosophy or thesis early in the work, using the remainder to establish processes, outline procedures, define structures, and delineate the logic of how these elements combine to form a desirable whole. This text does not formally establish its philosophy until page 216. After this point, there is a wealth of information of value to the analyst/student, which is indicative of where the true beginning should have been.

At this point, details, such as the concept of deep think, defined earlier in the text are finally applied to the thesis, yet without specific delineation of its process. In fact, the authors even define their concept of deep think as: "We use the term deep think to mean taking the time and expending the mental energy to think about a subject deeply and critically" (p. 154). This is an obvious circular argument. Much later in the text (p. 359) the authors delve into the dynamics of deep think sufficiently to identify it as the need for self-perception of attitudes and biases that influence our own thought processes and use this knowledge as a primary factor in any analytical compilations. This aspect is solid gold and is a critical element missing in both the professional discipline of intelligence and educating it.

Finally, there are many sections of the text where the authors develop concepts and itemized lists/checklists for the collection of useful, complex environment information only to then turn around and denigrate the concept as either undoable or cost-adverse. Specifically:

Gaining physical access to difficult targets in [irregular warfare] is important but usually difficult (170).

... sometimes direct access is clearly too difficult or perhaps not even possible [to achieve] (171).

Unfortunately, [to create the appropriate HUMINT collection capability defined in this text] we would need several networks of networks scattered around the world in potential insurgency and terrorist hot spots. That might prove infeasible owing to costs, low returns on places in which an insurgency never emerges, and the always present specter of people simply milking money and producing false or very sketchy data - a cost/benefit issue (247).

We must also admit that we cannot seek and find the detailed, pertinent data that commanders in IW [irregular warfare] situations require . . (p. 254).

As stated earlier, once the reader is past the first hundred or so pages, the text begins to outline many significant and important aspects of how intelligence collection should be performed, and 
often is not. In this single aspect, the book is worth reading if only to reestablish the structures that should exist and be taught in the intelligence community. This is not stating that these structures are NOT being taught or that there are not other, better texts in existence to achieve this goal more efficiently.

The book can, and does, present the semiotics approach to intelligence collection however, with the disturbing omission or unawareness that the true nature and neurological processes of cognition have yet to be discovered and defined. Many theories exist as do a plethora of philosophies, however, all are based upon a non-existent knowledge of how humans actually generate thoughts, ideas, concepts, etc. out of little-to-no previous knowledge. This aspect will remain true until cognitive science is able to succinctly establish the process of human thought.

While I would not purchase this book at the asking price, I am now interested in reading his remaining works out of simple curiosity to understand BG Hall and his philosophy better. However, I would never require any of my students to read this text unless part of a dissertation source review on the comparison of standard intelligence cognition techniques to semiotics, and then only after cautioning advisements.

Harry I. Nimon, Ph.D., Henley-Putnam University 